\title{
ROLLING CONTRACT FORMATION AND THE U.C.C.'S APPROACH TO EMERGING COMMERCIAL PRACTICES
}

\author{
Andrew Vogeler ${ }^{*}$
}

\section{INTRODUCTION}

In the years since the rolling contract formation theory developed, there has been a notable dissonance between the quiet acceptance of the theory by courts in numerous jurisdictions and the frequent and often severe criticism it receives from legal commentators. Scholars are often dismissive of the commercial efficiency rationales courts have applied in adopting the theory; ${ }^{1}$ viewing such rationales as an imbalanced judicial give-away to corporations at the expense of consumers. ${ }^{2}$ However, they tend to focus on the view that rolling contract theory is an illegal aberration from accepted contractual formation that leaves consumers to the mercy of an unfair bargaining disadvantage where they can be forced to accept detrimental terms and conditions without real knowledge or consent. ${ }^{3}$

The purpose of this article is to show that in fact rolling contract theory is quite consistent with the Uniform Commercial Code's policy supporting flexibility in contract formation to support the development of commercial practices. It is not simply a giveaway to sophisticated sellers, but is built in large part on the expectations of consumers. Moreover, taken in the context of existing practices, especially standard form contracts, it actually provides more transactional security to consumers than long-standing alternative practices. Finally, I will argue that the contractual formalism rationale, by which critics of rolling contract theory advocate a reversal of the clear judicial

\footnotetext{
* J.D. candidate, University of Pittsburgh School of Law, May 2012; B.A. New York University, 2009. With thanks to Professor Harry Flechtner for his inspiration and advice, to my parents for their endless love and support and most of all to the dedicated and superbly talented staff of the Journal of Law and Commerce, whom I was so honored to lead and serve.

1. See, e.g., Sajida Mahdi, Gateway to Arbitration: Issues of Contract Formation Under the UCC and the Enforceability of Arbitration Clauses Included in Standard Form Contracts Shipped with Goods, 96 Nw. U. L. REV. 403, 403-04 (2001).

2. See, e.g., Roger C. Bern, “Terms Later" Contracting: Bad Economics, Bad Morals, and a Bad Idea for a Uniform Law, Judge Easterbrook Notwithstanding, 12 J.L. \& PoL'y 641, 696 (2004).

3. See, e.g., William Lawrence, Rolling Contracts Rolling Over Contract Law, 41 SAN DiEGo L. REV. 1099, 1116-17 (2004).
} 
trend, is not only inconsistent with the U.C.C., but is at the same time inadequate, disproportional, and unnecessary to the goal of protecting consumers from unfair terms. It is inadequate because consumers are still subject to other types of standard form or adhesion contracts, which in practice give them less bargaining leverage to protect their interests than rolling contracts. It is disproportional because it would eliminate the benefits rolling contracts have provided to millions of consumers in the form of transactional efficiency and convenience, for the more limited purpose of preventing bad outcomes in the tiny fraction of contracts that end in dispute. Finally, it is unnecessary because there are more direct measures available for protecting consumers from abuse that already exist in the form of judicial doctrines and regulation.

\section{Commercial Practice and the Standard Form Contract CONTEXT}

Critical to understanding the legal and commercial context in which rolling contract theory developed is the idea of a contract law that is flexible to the needs and changes of commercial practice, particularly exemplified by standard form contracts. The essential purpose of standard form contracts is to bundle legal terms applicable to the sale of a product with the product itself, such that they are commoditized and offered on a take-it-or-leave-it basis. ${ }^{4}$ The subject matter of the terms, including choice of law and forum or arbitration clauses, warranties, remedies, and other customer service policies, are determined as part of the economic and legal risk elements of the product's marketing development. By offering uniform terms, sellers can streamline their marketing and save tremendously on the agency and transaction costs that would be associated with individually-negotiated agreements. ${ }^{5}$ This in turn, allows for wider distribution and easier entry into the national market since the terms of sale for a product can be standardized for mass-markets just as the qualities of the product are. ${ }^{6}$ A consequence of these terms is that they are no more negotiated by individual consumers than the price or quality of the goods, but theoretically, they are subject to the same competitive forces. If consumers don't like the terms, they won't buy the

4. John J.A. Burke, Contract as Commodity: A Nonfiction Approach, 24 Seton Hall Legis. J. 285, 287 (2000).

5. Jonathan Klick, The Microfoundations of Standard Form Contracts: Price Description v. Behavioral Bias, 32 Fla. St. U. L. Rev. 555, 556 (2005).

6. Burke, supra note 4 , at 287. 
goods and the seller will be pressured to either give more favorable terms or else attract customers with lower prices or higher quality.

An important preliminary issue presented by standard form contracts is how easily their terms can become a part of a contract. Will terms with results that clearly favor the seller be enforced even though the buyer is unable to remove the term through bargaining and may not have a practically realistic opportunity to read or understand the terms? This was a central issue addressed by the United States Supreme Court in Carnival Cruise Lines, Inc. v. Shute.

\section{A. Carnival Cruise Lines and Adhesion Contracts}

The U.S. Supreme Court in Carnival enforced a forum-selection clause printed on the back of a cruise ticket. ${ }^{7}$ The plaintiffs in the case had already paid for the tickets before receiving them in the mail or viewing the terms listed on them. ${ }^{8}$ Included in the terms was a clause stating that by accepting and using the tickets, the holder agreed to bring any dispute arising from the cruise in Florida. ${ }^{9}$ Unfortunately, the plaintiffs suffered an injury during the cruise and filed suit in their home state of Washington. ${ }^{10}$ Carnival Cruise Lines sought to have the forum-selection clause enforced and ultimately prevailed, with the Court holding that the clause was enforceable even though the plaintiffs had not read it and may not have had notice of it before purchasing the tickets because they were still responsible for the terms to which they legally assented. ${ }^{11}$ Only if the clause was unreasonable would it not have been enforced. ${ }^{12}$ The Court determined that because Florida is the primary seat of Carnival Cruise Lines, it was a reasonable forum to choose. ${ }^{13}$ This was true even though the plaintiffs were from Washington and their cruise departed from California. ${ }^{14}$ The Court reasoned that Carnival had legitimate reason for limiting its risk of litigation from any potential forum in which its customers resided..$^{15}$ Additionally, litigants from both sides would

7. Carnival Cruise Lines, Inc. v. Shute, 499 U.S. 585, 597 (1991).

8. Id. at 587

9. Id. at 587-88.

10. Id. at 588 .

11. Id. at 597 .

12. Id. at 593 .

13. Id. at 595 .

14. Id. at 587-88.

15. Id. at 593 . 
save time and expense from pre-trial motions to determine the proper forum. ${ }^{16}$ Finally, the customers may benefit by reduced fares "reflecting the savings that the cruise line enjoys by limiting the fora in which it may be sued." 17

The Court had to balance the practicalities of setting terms and providing notice to customers against the customers' reasonable opportunity to bargain over that term. The Court chose to allow the term even though they were incorporated without negotiation or bargaining parity on the part of the customer because of the business context in which the contract was executed. ${ }^{18}$ Thus, practically speaking, it would be meaningless to make the term negotiable, if the buyer has no parity, and it would be senseless to refuse to enforce a clause in a form ticket just because it was not negotiated so long as it was assented to. ${ }^{19}$

The very idea of form contracts is that there is no individualized bargaining because they are meant to provide "one-size-fits-all contracts" which promote uniformity of seller policies, therefore reducing agency costs, while also reducing transaction costs by tying the terms and conditions to the value of the marketed goods themselves. ${ }^{20}$ Indeed, a great lack of parity between the parties is "the norm." ${ }^{21}$ Because of this, at least one commentator has argued that a form contract is "tantamount to a commodity," where "[t]he contract is embedded in the product and constitutes part of its identity. The properties of the contract can no more be changed than the properties of the product itself, because the contract's properties, like the product's, are preset prior to being offered on the market." 22

Thus, in determining the true interest of the customer with respect to the reasonableness of the forum selection clause, one should consider the effects on the cruise ticket market, not the narrow legal effects on the individual sale, because it is in the market setting that the bargain takes place. This seems to have been the approach the Court took. It is easy, after all, to have sympathy for consumers who face difficulty as a result of a forum selection clause in seeking to make their case. However, this is a hindsight perspective. The vast majority of passengers do not face litigation, and thus a rational consumer will choose the cheaper tickets with a low risk of an unfavorable forum selection

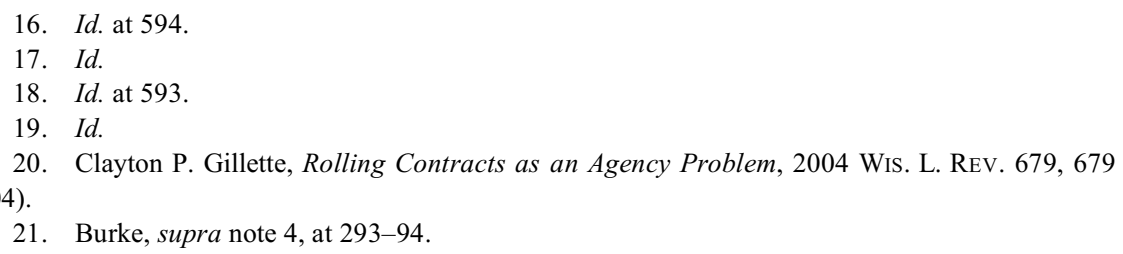


rather than a more expensive ticket with a favorable forum selection clause. Which is the greater benefit, the reduced prices for the great majority or the possibility of litigating in a chosen-forum in the rare event of litigation? For better or worse, the Court chose the same side as the market had and as the Shutes had when they agreed to Carnival's terms with its attendant conditions.

\section{RolLing CONTRACTS}

Rolling contract formation is in reality a method for forming standard form contracts. They have in common their origins in commercial practicality. Moreover, their benefit is visible in the market setting, with individual benefit deriving from participation in that market. Their most controversial feature is that they tend to involve payment for and delivery of goods before the buyer has a chance to view or assent to the standardized terms. However, the purpose for this is that because the consumer does not negotiate the terms, but merely chooses to buy or not buy the products with their attached terms, the buyer should not be delayed in their purchase by an empty formality for adhering to the standard terms and conditions, but should be able to order and pay for the goods so as to receive them as quickly as possible. The terms are sent later with the option of declining to complete the sale indicated by return of the goods. The option to decline the final purchase may be motivated by disapproval of the terms and conditions or other factors. In sum, the contract formation process can be called "rolling" because it rolls along simultaneously with the purchase and delivery process.

\section{A. The Typical Rolling Contract Situation}

The essence of a rolling contract is that in situations to which it can be applied, terms are enforced as part of a sales contract even though the buyer does not receive or have a chance to review them until after paying for the goods. However, it is a challenging legal theory to unpack because courts must not only understand and correctly apply the legal reasoning, but must also properly identify the type of situation in which it is relevant. In the following section, I will draw from a number of rolling contract cases to suggest four factors which have tended to trigger rolling contract analysis and may serve to identify a typical situation to which rolling contract analysis should apply. Then, I will synthesize the legal reasoning of these cases as they have applied to those factors with the result of enforcement of the disputed contract provisions. 
The factors that characterize a rolling contract situation include first, that the buyer should have been aware of or should have reasonably expected at the time of purchase that the sale would be subject to more terms than were specifically available at that time. Second, the additional terms should be unconditional, which is to say that the seller should only be willing to complete the sale upon acceptance of those terms. Third, the buyer should have opportunity to read and consider, and either accept or reject those terms before finalizing or canceling the sale. Finally, the buyer should have the opportunity to return the goods and have payment returned should she reject the terms.

1. The Buyer Should Reasonably Expect Terms Additional to Those Available at Time of Purchase

The Seventh Circuit's ProCD, Inc. v. Zeidenberg gives perhaps the clearest example of a case in which the buyer had notice at the time of sale that the contract would include terms beyond whatever may be said to have existed at the time of purchase. Matthew Zeidenberg selected software off of the shelf of a retailer, which included written notice on the outside of the box indicating that the purchase would be subject to a license agreement. ${ }^{23}$ Here, there was no dispute as to whether Zeidenberg was aware of the license agreement; he simply did not comply with its terms, believing that they were not binding. ${ }^{24}$

Not long after the ProCD decision, the Seventh Circuit indicated in Hill v. Gateway 2000, Inc. that a rolling contract situation could exist even where it was not clear that the buyers actually knew additional terms were forthcoming, so long as they should have known. Judge Easterbrook states that "the Hills knew before they ordered the computer that the carton would include some important terms ...." ${ }^{25}$ He does not explain directly how it was determined that they knew this, but describes from the evidence that Gateway advertises warranties and lifetime support services, which a reasonable shopper would expect to have detailed as part of any purchase agreement. ${ }^{26}$ Thus, it seems, rolling contract analysis could apply where under the

23. ProCD, Inc. v. Zeidenberg, 86 F.3d 1447, 1450 (7th Cir. 1996).

24. Darren C. Baker, ProCD v. Zeidenberg: Commercial Reality, Flexibility in Contract Formation, and Notions of Manifested Assent in the Arena of Shrinkwrap Licenses, 92 Nw. U. L. REv. 379, 380 (1997).

25. Hill v. Gateway 2000, Inc., 105 F.3d 1147, 1150 (7th Cir. 1997).

26. Id. 
circumstances, the buyer should have expected that additional detailed terms would arrive in accordance with expectations of what would be part of the seller's obligations.

This view was accepted by the Supreme Court of Oklahoma, which stated that terms could be enforced even though plaintiffs do not receive them until after placing an order if the "language and circumstances" are such that the contract including those terms is not formed until after the order is placed. ${ }^{27}$ The Court did not, however, have sufficient evidence to conclude whether or not the language or circumstances indicated a rolling contract and remanded on that basis. ${ }^{28}$

This view was also adopted by the Supreme Court of Rhode Island, which more explicitly stated that a reasonable consumer, in the specific case of a telephone order, would not expect or want to hear every term read over the phone so that all terms could be assented to at point of purchase..$^{29}$ But at the same time, a reasonable consumer would not believe that absent those terms, the contract has been concluded. ${ }^{30}$ The Court concludes, "[r]ather, [the consumer] is aware that with delivery comes a multitude of standard terms attendant to nearly every consumer transaction." ${ }^{11}$ Thus, the court is even willing to presume that in a typical consumer transaction such as the one disputed, where reasonable practice would indicate that the terms would be more effectively communicated after the time of purchase, the contract will not form at the time of purchase, but after the consumer has received and had a chance to accept or refuse the terms. ${ }^{32}$

The Supreme Court of Kansas appears to have taken a different approach in Wachter Management Company v. Dexter \& Chaney, Inc., but factual distinctions explain this difference. The Court held that a software "shrinkwrap" license was not enforceable as part of the contract where the buyer was not aware at the time of signing the agreement that any additional license terms would be involved. ${ }^{33}$ Distinctions in the facts of this case include that it was a business to business agreement that was developed "[a]fter detailed negotiations." ${ }^{34}$ Further, the contract was not said to form through the exchange of money for a promise, such as a typical consumer purchase, but

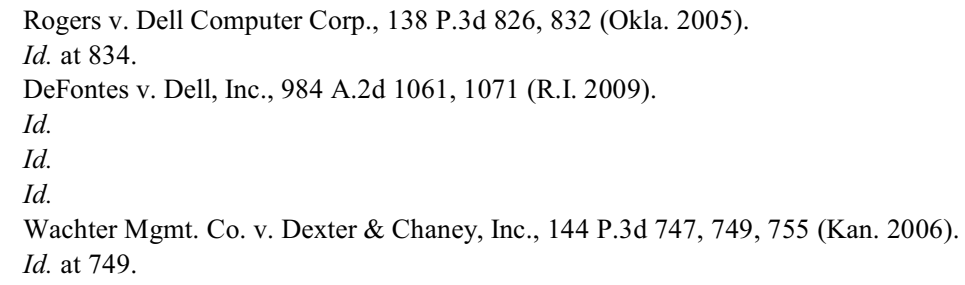


was formed by the exchange and signing of forms. ${ }^{35}$ Thus the kinds of reasonable behavior and expectation that might be inferred from a typical standard form transaction will not apply to a closely negotiated agreement. Therefore, although the outcome is different, the reasoning, which relies on the language and circumstances, is parallel to prior rolling contract cases.

\section{Acceptance of Additional Terms Should Be an Unconditional Element of} Acceptance of the Agreement

It is axiomatic that if acceptance of a contract depends upon acceptance of additional terms, there should be some indication with regard to those terms that if they are rejected, the entire agreement will be also. This proposition is supported in case law applying rolling contract analysis. In ProCD, the court refers to the very clear terms on the software box, which indicate restrictions and a license that apply to the software. ${ }^{36}$ Moreover, the CD-ROM is programed with a copy of the license, is accompanied by a manual containing the license and every time the program runs, it displays the license. ${ }^{37}$ This license includes restrictions on how the program may be used..$^{38}$ Thus, acceptance of the license is unambiguously required as a condition of purchasing and using the software.

The court in Hill also clearly indicates that the terms that arrived with the computer would govern "unless the customer returns the computer within 30 days." ${ }^{39}$ The court in Brower cited these same terms. ${ }^{40}$ Even the court in DeFontes, though ultimately refusing to enforce the terms as part of the agreement on separate grounds, noted that the language of the terms "certainly informed [buyers] that [the seller] intended to bind them to heretofore undisclosed terms and conditions ...." ${ }^{\prime 1}$

A case that exemplifies a court refusing to include a purported set of additional terms on these grounds, however, is Sprecht v. Netscape Communications Corp. There, the buyer had downloaded free software from Netscape and was alleged to have accepted an arbitration clause as part of an attached license agreement. ${ }^{42}$ Because the software download was free and

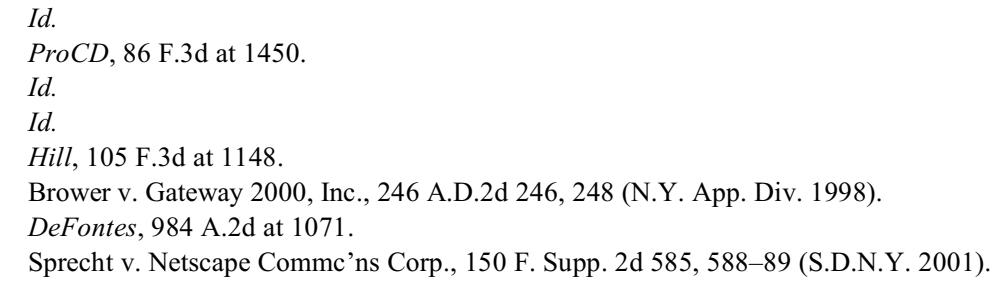


entirely electronic, there was some question as to whether Article 2 of the U.C.C. even applied. ${ }^{43}$ The court determined that it did, reasoning that the parties had essentially the same relationship as in a typical standard-form, buyer-seller contract. ${ }^{44}$ But the court also noted that in this case "the user need not view any license agreement terms or even any reference to a license agreement, and need not do anything to manifest assent to such a license agreement" in order to download the software. ${ }^{45}$ In fact, the visitors were only "invited" to review and agree to the license material, but by the language of the license were not required to accept. ${ }^{46}$ Thus, absent an indication that the terms must become part of the agreement, the buyer was not required to accept the additional terms in order to accept the contract. For this reason, the additional terms were not included in the contract, however, by the same reasoning, it appears that had acceptance of the terms been mandatory, they would have been included.

\section{The Buyer Should Have an Adequate Opportunity to Accept or Reject the Additional Terms}

This factor, much as the one requiring at least reasonable awareness of additional terms, can pose challenges of factual interpretation distinguishing a situation in which the buyer clearly knew of the possibility and means of rejection from a situation in which the buyer never knew of such opportunity but should have under the circumstances. As we have seen, the buyer in ProCD was given notice that by using the purchased software he would accept the terms of the license, but chose to use it anyway, believing the terms were not enforceable. ${ }^{47}$ Likewise, the buyer in Hill was aware of the statement of additional terms, which clearly explained that the terms could be rejected by returning the goods within thirty days.$^{48}$ The court in Brower was not clear as to whether the buyer had actual knowledge of the additional terms, but noted that the language stating acceptance of the terms if the computer is not returned in thirty days is clearly present and applicable. ${ }^{49}$ The specific clause

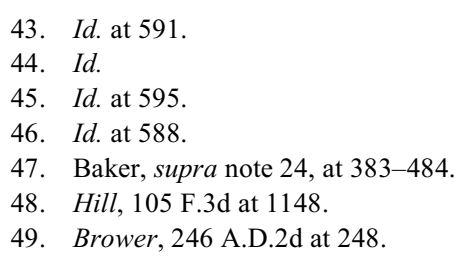


at issue was ultimately not enforced, but that was due to unconscionability, not a holding that the additional terms were not part of the contract. ${ }^{50}$

Alternatively, the Supreme Court of Rhode Island held that disputed additional conditions were not part of the contract between the buyer and seller, stating, "[i]n reviewing the language of the terms and conditions agreement it cannot be said that it was reasonably apparent to the plaintiffs that they could reject the terms simply by returning the goods." ${ }^{51}$ Thus, even if the additional terms are adequately delivered, if the buyer is not given adequate notice that the terms may be rejected, they will not be included as part of the contract. This compels the seller to ensure the buyer reasonably expresses assent by keeping the goods, or otherwise acting to accept the terms in accordance with the contract.

4. The Buyer Should Be Able to Reject the Additional Terms and Be Refunded the Sale Price

It is clear in the Seventh Circuit cases that the buyers were entitled to a refund had they rejected the goods. In ProCD, Judge Easterbrook observes "a right to return the software for a refund if the terms are unacceptable. ${ }^{, 52} \mathrm{He}$ does not specifically mention the right to a refund on return as a point in dictum in Hill, however, given the reliance of this decision on ProCD generally and the description of the payment as a means of expediting the contract performance alongside its formation, it is difficult to imagine why Gateway could ever be entitled to payment for a contract that was never concluded. ${ }^{53}$

In fact, a later case from the Northern District of Illinois reached the same conclusion, stating, "the customer could return the product without penalty." 54 Notably, the buyer in this case never claimed that the clause at dispute was not part of the contract. ${ }^{55}$ Nevertheless, the court suggested that because the terms made it appear that a return would not result in a full refund, it probably would not have provided the buyer an adequate chance to reject the terms. ${ }^{56}$ Consequently, rejection of the terms would not actually result in cancellation

50. Id. at 254 .

51. DeFontes, 984 A.2d at 1073.

52. ProCD, 86 F.3d at 1451 .

53. Hill, 105 F.3d at 1150 .

54. Trujillo v. Apple Computer, Inc., 578 F. Supp. 2d 979, 994 (N.D. Ill. 2008).

55. Id. at 981 .

56. Id. at 993 . 
of the performance requirements of the buyer, suggesting that the contract had been formed before the addition of the later terms. If this were true, there could certainly be no rolling contract.

\section{B. Legal Support for Rolling Contract Formation}

Having evaluated the factors of a typical situation in which a rolling contract is concluded, an explication of the legal reasoning supporting the finding of a rolling contract is more forthcoming. It must be emphasized from the outset that rolling contract theory is not about adding terms to an existing contract, but is about forming a single contract in a rolling process so that a standardized transaction can be made more efficient by synchronizing significant performance aspects with the formation of the agreement itself. The reader will recall, for example, the statement of the Supreme Court of Oklahoma that "[i]f the language and circumstances were such that when the orders were placed, the contracts were not formed until after the plaintiffs received the 'Terms and Conditions of Sale' document, the [disputed terms] would be a term of the contracts." ${ }^{57}$ Thus, the issue is not whether the disputed terms will be added to an existing contract, but whether a contract in fact did form at point of purchase, or if it was only concluded after the incorporation of the "Terms and Conditions of Sale."

The reasoning of the Seventh Circuit regarding this issue is the same. In Hill, Judge Easterbrook observed,

[t] ] question in ProCD was not whether terms were added to a contract after its formation, but how and when the contract was formed-in [sic] particular, whether a vendor may propose that a contract of sale be formed ... with money or a general 'send me the product,' but after the customer has had a chance to inspect both the item and the terms. ${ }^{58}$

The New York appellate court in Brower agrees, noting:

[I]n such transactions, there is no agreement or contract upon the placement of the order or even upon the receipt of the goods. By the terms of the Agreement of issue, it is only after the consumer has affirmatively retained the merchandise for more than 30 days - within which the consumer has presumably examined and even used the product(s) and read the agreement - that the contract has been effectuated. ${ }^{59}$

57. Rogers, 138 P.3d at 832 .

58. Hill, 105 F.3d at 1150 .

59. Brower, 246 A.D. $2 \mathrm{~d}$ at 251. 
If the means of contract formation, therefore, are clear, what does Article 2 of the U.C.C. say about the ability of the parties to form a contract in this way?

\section{U.C.C. Article 2-204 Offers Flexibility in the Means of Contract Formation}

The U.C.C. recognizes that "[a] contract for sale of goods may be made in any manner sufficient to show agreement, including conduct by both parties which recognizes the existence of such a contract." ${ }^{\circ 0}$ This flexibility, of course, means that varying interpretations of similar facts may result in diverging findings as to whether and how the contract was formed. Thus, the court in ProCD allowed the seller, which it viewed as "master of the offer" to invite acceptance by the conduct of keeping and using the goods, which acceptance included acceptance of the user restriction terms ${ }^{61}{ }^{1}$ In contrast, the U.S. District Court of Kansas found sufficient agreement for a sales contract from the payment for and reception of a computer on the part of the buyer." ${ }^{2}$ It found so by adopting the same reasoning from Step-Saver Data Systems, Inc. v. Wyse Technology. ${ }^{63}$ In that Third Circuit case, the court saw "no need to parse the parties's [sic] various actions to decide exactly when the parties formed a contract. [Seller] has shipped the product, and [buyer] has accepted and paid .... The parties's [sic] performance demonstrates the existence of a contract." ${ }^{964}$ Indeed, even though rolling contract formation all but requires knowledge of when the contract is formed, the court in Step-Saver was correct under Article 2-204 of the U.C.C., which states that "[a]n agreement sufficient to constitute a contract for sale may be found even though the moment of its making is undetermined." ${ }_{65}^{5}$ Further, it provides that "[e]ven though one or more terms are left open a contract for sale does not fail for indefiniteness if the parties have intended to make a contract ...." ${ }^{96}$ Thus, Judge Easterbrook's supposition that the contract between the Hills and Gateway would be "termsfree" absent the inclusion of Gateway's additional terms appears to be false. ${ }^{67}$ In sum, the default provisions of the U.C.C. would clearly apply absent terms

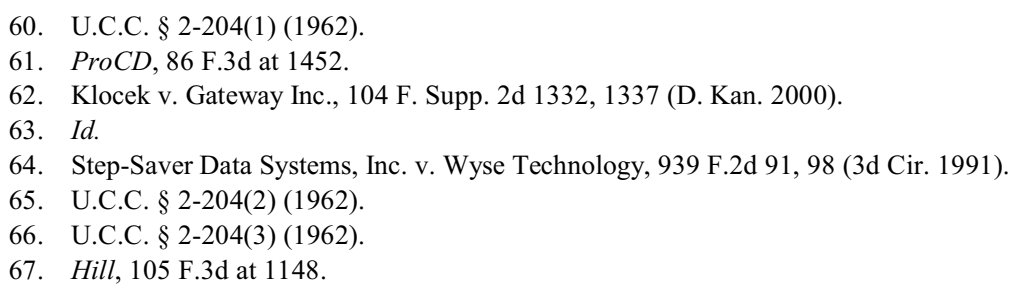


agreed to by the parties varying their effect. ${ }^{68}$ This could include, for instance, the implied warranties of merchantability and fitness for a particular purpose. $^{69}$

Although § 2-204 allows finding of a contract even by conduct, even if it is not clear when the contract formed and even though terms are still missing, it does not require that a contract be found simply because two parties' conduct suggests the possibility of one. The official comments to $\S 2-204$ make clear that the decisive issue is what the parties actually agreed, which may involve consideration of all of the circumstances of the transaction..$^{70}$ The challenge facing courts in these cases therefore, is that they must find the agreement first and determine its objective meaning, usually by inferring from the parties' conduct under the circumstances, before they can find whether a contract has been formed and how. What should guide them in these inferences? One important factor is the mandate to interpret the U.C.C. according to its purposes and policies, which include "[permitting] the continued expansion of commercial practices through custom, usage, and agreement of the parties." of the parties in a rolling contract situation would not be left to a guess as to the subjective expectation of the parties at the time of purchase, but would include consideration of what that intent reasonably would have been in light of the commercial practice in which they were engaged. Furthermore, the policy allowing new commercial practices allows such interpretation in the context of practices that did not exist when the U.C.C. was drafted or had not previously been recognized in case law.

In Klocek, the Federal District Court of Kansas criticized Judge Easterbrook's finding in ProCD that the vendor is the master of the offer, noting that "[i]n typical consumer transactions, the purchaser is the offeror, and the vendor is the offeree." 72 This was significant as a legal matter, because Judge Easterbrook had relied on a finding that the vendor was the master of the offer to conclude that ProCD was able to invite acceptance by its rolling contract process, rather than by accepting money in exchange for delivery. ${ }^{73}$ Of course, U.C.C. § 2-204 does not require finding who is the offeror and offeree to determine whether a contract is made, but if there is such evidence,

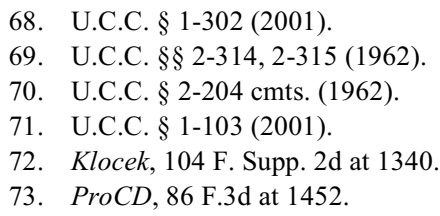


it will help to determine whether and how the parties intended to form a contract. ${ }^{74}$ The court in Klocek rejected the vendor-as-offeror because it found no factual evidence that Gateway was the offeror in its contract with Klocek. ${ }^{75}$ The court indicates that to find that the vendor was the offeror, it would have had to have given a price quote with the reasonable appearance that assent to the quote would form a contract. ${ }^{76}$ This reasoning is clearly couched in the traditional commercial practice of an over-the-counter purchase, but it does not reflect the commercial reality of the rolling contract situation at issue.

Judge Easterbrook more satisfactorily incorporates the commercial practice between the buyer and seller in ProCD and Hill in determining that the vendor is the offeror, but he is unfortunately not very clear in explaining why this is so..$^{77}$ The reasoning is easier to see in ProCD. The buyer bought the software in a box at the store that had notice on the box that the purchase would be subject to a user license. ${ }^{78}$ If the seller sets out the terms by which the buyer may purchase the product and that the seller's terms must be accepted before the agreement will be concluded, then it is fairly clear that the seller is the offeror. The seller expressly excludes the possibility that payment alone is sufficient to complete the sale. Further, the terms included clearly "manifest willingness to enter a bargain" and invite the buyer to assent to the terms so as to conclude the bargain, in conformance with the definition of an offer in the Restatement (Second) of Contracts. ${ }^{79}$ The seller, as maker of that offer is the offeror.

This reasoning is more difficult to discern in Hill. The buyers did not receive the terms before the time of purchase, nor do the facts show that they were given formal indication that terms were forthcoming, as in ProCD, which would have to be accepted in order to accept the contract. Nevertheless, Judge Easterbrook concludes that the buyers were aware that their purchase would be subject to further terms. ${ }^{80}$ He refers to Gateway advertisements about warranties and support services that accompany the computer, ${ }^{81}$ and indicates that the Hills actually invoked those warranties earlier in their dispute process. ${ }^{82}$ Finally, though the Hills did not receive these terms before

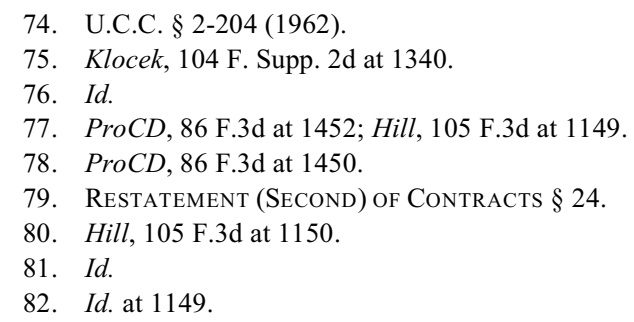


submitting payment, this was because they placed their order over the phone, and it would have been impractical to include all of the terms before payment. ${ }^{83}$ Even still, shouldn't the Hills have received notice that additional terms would be part of the purchase? Arguably they did have notice. U.C.C. $\S 1-202$ provides that "a person has 'notice' of a fact if the person:

(1) has actual knowledge of it;

(2) has received a notice or notification of it; or

(3) from all the facts and circumstances known to the person at the time in question, has reason to know that it exists." 84

The Hills may not have had actual knowledge that there would be terms in addition to what was discussed over the phone, nor do they seem to have received notice, such as the box message in ProCD, but Judge Easterbrook found that under the circumstances they had reason to know additional terms would be forthcoming. Otherwise, they could not receive the warranty and service protection they expected. Ultimately, then, the Hills knew or should have known that their purchase could only be finalized by accepting forthcoming terms from the seller. Judge Easterbrook reasoned that this was because the seller was the offeror and made acceptance conditional on acceptance of the additional terms. ${ }^{85}$ This view is problematic because the Hills may not have been expressly aware that there would be additional terms assent to which would be required to enter the contract. However, at the very least, given the circumstances, they should have been aware that their payment alone did not conclude the contract.

It is very often the case, as the court in Klocek observes, that contracts are formed by over-the-counter exchange of payment for goods in perfect accordance with U.C.C. $§ 2-204 .{ }^{86}$ However, such accordance does not come from the form of the transaction or its traditional acceptance, but from the sensibility of such a conclusion in light of the commercial practice involved. Regardless of who is the offeror or offeree, the particular nature of the transaction in Hill, and similar cases, justifies a different analysis of whether a contract is formed at payment. When products being sold are sophisticated, such as computers, software, satellite dish equipment and other technical goods, they tend to be accompanied by detailed warranty and service provisions. ${ }^{87}$ Yet it may be impractical and inconvenient to the buyer and

83. $I d$.

84. U.C.C. § 1-202(a) (2001).

85. Hill, 105 F.3d at 1149.

86. Klocek, 104 F. Supp. 2d at 1340.

87. Hill, 105 F.3d at $1149-50$. 
seller to include all of these terms at the point of purchase. ${ }^{88}$ Further, given the scale of marketing involved in the sale of computers and software, it is reasonable to assume that sellers will offer uniform terms to all purchasers, without individual negotiation, to promote efficiency and standard policies. ${ }^{89}$ Under these circumstances, it is unreasonable for the buyer to believe the contract is concluded by payment alone, when these additional terms have yet to be received or assented to. ${ }^{90}$

Thus, where U.C.C. $§ 2-204$ provides broad flexibility in the means of contract formation, that in principle could support finding a sale contract at time of order, payment, delivery, or after receipt of and assent to terms, it is the reasonable expectation of the parties under the circumstances that determines whether a contract has formed, not the mere possibility that a contract was formed. The reasonable intent of the parties can be determined by inference from their conduct in light of commercial practice, even if that practice is new. The commercial realities and practice that accompany rolling contract situations strongly suggest that it would be unreasonable to infer that the seller intended to be bound at time of payment or that the buyer expected to be bound. This is particularly true in situations, like ProCD, where the seller is the master of the offer and clearly indicates that neither payment nor acceptance of delivery is sufficient to accept the sale offer.

\section{The Circumstances of Rolling Contracts Unambiguously Exclude Default} Provisions of U.C.C. $\$ 2-206$

The same circumstances which indicate that the contract is formed by assent on the part of the buyer to the seller's terms in rolling contract situations, rather than at payment or delivery of the goods, also indicate that arguments that U.C.C. $\S 2-206$ precludes rolling contract formation ${ }^{91}$ are incorrect. ${ }^{92}$ First, the circumstances of a rolling contract situation often

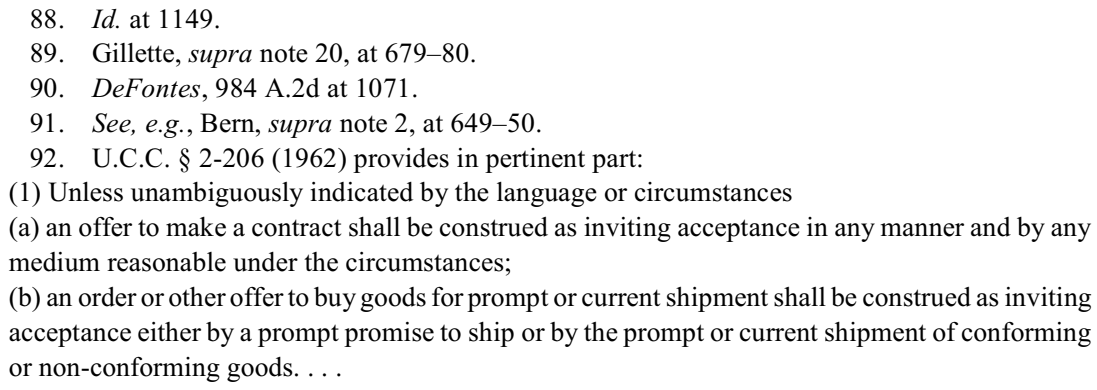


unambiguously indicate that acceptance is not invited "in any manner and by any medium reasonable in the circumstances." ${ }^{93}$ In a situation like ProCD, where the buyer clearly has notice that acceptance of additional terms are requisite to conclusion of the contract, the situation is unambiguous that the buyer may only accept the offer by acceptance of the terms. ${ }^{94}$ In a situation like that in Hill, even if the circumstances are considered ambiguous as to whether any reasonable means of acceptance are available, it would be unreasonable to believe that payment or delivery alone are reasonable means of acceptance because those means do not include assent to the forthcoming terms, which the reader will recall, should be expected to be an unconditional part of the agreement. ${ }^{95}$ So long as the seller is considered the offeror, therefore, acceptance of the terms is unambiguously required to accept the contract, such that any means short of that would either be ineffective or unreasonable under $\S 2-206(1)(a)$.

Even if the buyer were the offeror, however, so as to implicate $\S 2-206(1)(b)$, the circumstances of a rolling contract situation unambiguously indicate that "an order or offer to buy goods for prompt or current shipment" does not invite acceptance by promise to ship or prompt shipment. ${ }^{96}$ Recall, for example, that in Hill the buyers not only expected additional terms with respect to warranties and support services, they actually invoked them early in their dispute with Gateway. ${ }^{97}$ This clearly indicates their intent that the contract not be formed until after receiving and assenting to those terms. It would be unreasonable to assert that they both invited acceptance of a contract without those terms by shipment of the goods, and yet expected those terms to be a binding part of the contract. Thus, in a rolling contract situation, because both parties expect that terms in addition to those known or assented to at time of payment or delivery will be a part of the contract, the circumstances unambiguously indicate that no acceptance which results in the exclusion of those terms will have effect, nor would any such acceptance be reasonable.

\footnotetext{
93. U.C.C. $\$ 2-206(1)(a)(1962)$.

94. ProCD, 86 F.3d at 1450.

95. Hill, 105 F.3d at 1150.

96. U.C.C. § 2-206(1)(b) (1962).

97. Hill, 105 F.3d at 1150 .
} 


\section{U.C.C. § 2-207 Is Not Applicable to Rolling Contract Situations}

Discussion of $\S 2-207$ is at the eye of the storm in the controversy surrounding rolling contract formation. It seems clear that application of $\S 2-207$ would result in exclusion of terms received after payment in most rolling contract situations, and would essentially destroy the effectiveness of the transaction. ${ }^{98}$ Additionally, scholars easily point out the obvious error in Judge Easterbrook's reason for rejecting application of $\S 2-207$, with the effect of avoiding this outcome. ${ }^{99}$ Justice Easterbrook argued in both ProCD and again in Hill that § 2-207 was not relevant because it referred to "battle of the form" situations, when in these cases, there was only one form; the terms sent by the seller. ${ }^{100}$ In fact, $\S 2-207$ could easily involve one form. For example, suppose a non-merchant buyer and merchant-seller agreed over the phone to a sale. The seller sends a confirmation of the agreement with terms in addition to those agreed upon, but the buyer disregards that form, and both parties otherwise perform their obligations. Under these facts, the confirmation will operate as acceptance of the telephone agreement and conclude it as a contract, since acceptance is not expressly made conditional on assent to the additional or different terms. ${ }^{101}$ Because the buyer is not a merchant, the new terms are only "proposals for addition to the contract." 102 The failure of the buyer to accept those terms and the subsequent performance confirms that the additional terms do not become part of the original contract, so that the terms are excluded. ${ }^{103}$

This example is designed to parallel a rolling-contract situation in many respects, particularly the fact pattern in Hill. ${ }^{104}$ However, there are key differences, which indicate that Judge Easterbrook was correct in result, if not rationale, with respect to the applicability of $\$ 2-207$. Under the facts and circumstances of a rolling contract, the additional terms are neither sent as expressions of acceptance nor confirmation of an agreement. ${ }^{105}$ On the

98. The analysis in Klocek does particularly well in describing how § 2-207 would apply to rolling contracts.

99. See, e.g., Robert A. Hillman, Rolling Contracts, 71 Fordham L. Rev. 743, 753 (2002). Professor Hillman nevertheless supported rolling contracts under an interesting, if questionable, alternative theory.

100. ProCD, 86 F.3d at $1452 ;$ Hill, 105 F.3d at 1150.

101. U.C.C. § 2-207(1) (1962).

102. U.C.C. § 2-207(2) (1962).

103. U.C.C. § 2-207 (1962).

104. Hill, 105 F.3d at 1148 .

105. U.C.C. § 2-207(1) (1962) 
contrary, the reader will recall that the terms are in fact part of the offer. ${ }^{106}$ Thus there is no basis in $\S 2-207$ for concluding that the terms should operate as acceptance..$^{107}$ As such, there is no contract to which the terms could be proposed additions. ${ }^{108}$ In fact, the terms are part of an ongoing negotiation, to which $\S 2-207$ clearly does not apply.

It is understandable that a rolling contract process is difficult to explain in terms of the traditional narrative forms of legal analysis. Since when are contracts performed before they are formed? Judge Easterbrook offers a rhetorical answer to this question by citing examples of common transactions that involve payment and delivery for the product before the contract is fully formed. ${ }^{109}$ But these examples are somewhat beside the point. Rolling contract formation did not develop and was not accepted because it fits a simple, traditional legal paradigm, but because it reflects a commercially sensible approach to a type of sale that has become a common experience in our society and brings benefits to sellers and buyers alike. ${ }^{110}$ Under the express policy of the U.C.C., to require that commercial practice follow traditional legal paradigms would put the cart before the horse. Article 1-103 requires construction of the U.C.C. "to permit the continued expansion of commercial practices," not rejection of new practices because they don't comply with traditional applications of U.C.C. provisions. ${ }^{111}$ To be sure, the commercial practices must fit within the "liberally construed" provisions of the U.C.C. But the cases that have adopted rolling contract formation have demonstrated that the practice is consistent with those provisions.

\section{Formalistic Preclusion of Rolling Formation Will Harm Consumers More than Protect Them}

Preclusion of rolling formation is inadequate to protect consumers because rolling-formation is but one method of formation. The long accepted standard form contract allows sellers to include any term they might include in a rolling contract. The only difference is how the transaction works. In a telephone sale, short of reading the terms over the phone, ${ }^{112}$ the seller could

106. Hill, 105 F.3d at 1150 (citing ProCD, Inc. v. Zeidenberg, 86 F.3d 1447 (7th Cir. 1996)).

107. U.C.C. § 2-207(1) (1962)

108. U.C.C. $\S 2-207(2)(1962)$

109. ProCD, 86 F.3d at 1451.

110. Hill, 105 F.3d at 1149 .

111. U.C.C. § 1-103(a)(2) (2001).

112. Hill, 105 F.3d at 1149 (as Judge Easterbrook facetiously suggested). 
collect the buyer's relevant information, mail the terms and conditions to the buyer and await the buyer's assent before putting in the order and shipping the goods. The buyer is no more likely to read or understand all of the terms, but is more likely to be irritated by the seemingly needless delay and paper work necessary to get the goods. An online sale could certainly be faster. Before placing the order, the buyer could be required to check a "click-wrap agreement" which includes all of the seller's terms. But the buyer seems less likely than ever to read or understand the terms in this situation. Thus, this formality would hardly protect consumers in practice.

The better approach, however imperfect, is to use existing tools to protect consumers from unreasonable outcomes where the market is inadequate to address their vulnerability. Consumers may be protected by the judicial doctrine of unconscionability, which will void terms to which a reasonable consumer would not have knowingly assented and which causes undue hardship or surprise. ${ }^{113}$ Additional judicially enforced public policy may be applied as well, including unenforceability of arbitration clauses that preclude class-action suits. ${ }^{114}$ Finally, state and federal laws and regulations may be passed to protect consumers. These measures, although often seemingly inadequate in practice, are better than preclusion of an entire means of bargaining because they specifically address consumer vulnerabilities without disproportionately precluding the benefits that bargaining may provide to buyers and sellers.

\section{CONCLUSION}

As with standard form contracts, there are many latent dangers involved when contracting is commoditized to allow for mass-marketing. These agreements involve difficult trade-offs in risk-allocation, such as the allowance of arbitration-clauses to promote easier national-market entry and lower prices even if individuals who later want to litigate in court will find that they have waived their right to do so. The lower scrutiny standard form contracts receive also results in a higher potential for sophisticated companies to bind consumers to disproportionate terms. But, they also allow for sellers to structure their transactions in a way that is more responsive to marketing efficiency and consumer convenience. Any time a transaction involves

113. See, e.g., Brower v. Gateway, 246 A.2d 246 (N.Y.A.D. 1998). This is a famous example where the court actually refused to enforce an arbitration clause solely on grounds of substantive unconscionability, rather than also requiring procedural unconscionability.

114. See, e.g., Fiser v. Dell Computer Corp., 188 P.3d 1215 (N.M. 2008). 
delicate balances such as these, it is unwise to place threshold barriers to the way buyers and sellers can negotiate them because the perceived risks prevented are likely to be matched by benefits prevented. This is why the approach to contract formation in the U.C.C. embraced flexibility and deference to "the expansion of commercial practices." 115

In light of U.C.C. policies and the clear benefits rolling-contract formation has provided to consumers, many courts have embraced them. There is good reason for considering consumer protection in these kinds of transactions, and judges have an important role to play. But reverting to formalism in contract formation is as likely to harm consumers as to help them. For this reason, courts should be cautious in their interpretation of transactions, to be sure that parties are able to get the contract they bargain for during the transaction, not in light of preventing particular bad outcomes. Moreover, legal scholars should focus more on how to protect consumers in the context of efficient transactions rather than precluding transactional methodologies merely because they may pose dangers. 